\title{
Management of hypertriglyceridemia in uncontrolled type 2 diabetes mellitus patients: 2 case studies
}

\section{Introduction}

Hypertriglyceridemia (HTG) is diagnosed when the serum triglyceride (TG) level exceeds $150 \mathrm{mg} / \mathrm{dL}$. The Adult Treatment Panel III of the National Cholesterol Education Program has suggested four TG strata: normal $<150 \mathrm{mg} / \mathrm{dL}$, borderline high $150-199 \mathrm{mg} / \mathrm{dL}$, high $200-249 \mathrm{mg} / \mathrm{dL}$, and very high $>500 \mathrm{mg} / \mathrm{dL} .{ }^{1}$ HTG can be inherited as a primary familial trait in combination with dyslipidemia or can ocur secondary to uncontrolled diabetes mellitus, obesity, alcohol consumption or estrogen therapy. ${ }^{2}$ HTG is an important independent risk factor for cardiovascular disease and it is also associated with $1 \%$ to $7 \%$ of all cases of acute pancreatitis. ${ }^{3}$ TG levels greater than 1000 $\mathrm{mg} / \mathrm{dL}$ require urgent treatment to reduce the risk of pancreatitis. ${ }^{4,5}$ The standard treatment of HTG with omega 3 fatty acids and fibrates, along with dietary changes, has no effect on an emergency situation. Type 2 diabetes mellitus is also a known cause of HTG. In type 2 diabetes mellitus patients, the major cause of morbidity and mortality is cardiovascular disease regarding the lipid profile. Abnormalities in triglyceride rich lipoprotein (TRL) metabolism are cardinal features of type 2 diabetes. Metabolic dysregulation resulting in HTG include enhaced hepatic secretion of TRL due to insulin resistance and delayed clearence of TRL involving lipoprotein lipase (LPL)mediated lipolysis. ${ }^{6}$ When patients have diabetes mellitus and HTG both, cardiovascular risk and other complications as acute pancreatitis, peripheral venous thrombosis, pulmonary edema and rhabdomyolysis increase markedly. We aimed to present two uncontrolled type 2 diabetes mellitus patients with severe HTG (TG level $>1000 \mathrm{mg} / \mathrm{dL}$ ) who were treated succesfully with insulin infusion.

\section{Case I}

A thirty-two-year-old woman previously healthy, was admitted to our outpatient clinic because of abdominal pain, polydipsia and edema in her body. On physical examination, she presented with blood pressure (BP) $120 / 72 \mathrm{~mm} \mathrm{Hg}$, heart rate (HR) $84 \mathrm{bpm}$, respiratory rate (RR) $20 \mathrm{rpm}$, temperature $36,5^{\circ} \mathrm{C}, \mathrm{O} 2$ saturation 98 . Examinations of respiratory, cardiovascular, abdominal systems and extremities were all normal. She had no history of alcohol consumption. She had no diabetic retinopathy in her eye examination. Laboratory tests show; glucose $351 \mathrm{mg} / \mathrm{dL}$, TG $1316 \mathrm{mg} / \mathrm{dL}, \mathrm{HbA} 1 \mathrm{c} 14.7 \%$, ketonuria and glycosuria. We checked amylase and lipase tests which resulted as 27U/L-26U/L to exclude acute panreatitis. Abdominal ultrasound showed just signs of fatty liver and hepatomegaly $(168 \mathrm{~mm})$. So the patient diagnosed with uncontrolled diabetes mellitus with severe HTG. Intravenous fluid therapy and $0.1 \mathrm{U} / \mathrm{kg}$ insulin continuous perfusion iniated to control glucose and TG levels. TG level decreased progressively, and at 48 hours TG level dropped to $199 \mathrm{mg} / \mathrm{dL}$, LDL $136 \mathrm{mg} / \mathrm{dL}$, total cholesterol $211 \mathrm{mg} / \mathrm{dL}$ with this treatment. To exclude type 1 diabetes mellitus; insulin antibodies were negative, C-peptide $0.78 \mathrm{nmol} / \mathrm{L}$ and no metabolic acidosis. Glycemia were well controlled with subcutaneous insulin regimen (insuline glargine and insulin glulisine), negative glycosuria and ketonuria. She had no HTG again on her follow-up monitoring without medication.

\author{
Volume 3 Issue 4 - 2016
}

\author{
Betul Erismis,' Bahar Ozdemir,' Hakan \\ Kocoglu, 'Yıldız Okuturlar,' Hatice Kaya,' \\ Betul Yildirim,' Mehmet Hursitoglu,' Ozlem \\ Harmankaya,' Meral Mert ${ }^{2}$ \\ 'Department of Internal Medicine, Bakirkoy Dr Sadi Konuk \\ Training and Research Hospital, Turkey \\ 2Department of Endocrinology and Metabolism, Bakirkoy Dr \\ Sadi Konuk Training and Research Hospital,Turkey
}

\begin{abstract}
Correspondence: Betul Erismis, Department of Internal Medicine, Bakirkoy Dr Sadi Konuk Training and Research Hospital,Turkey, Tel +90532l 645 429, Email betul_erismis@yahoo.com
\end{abstract}

Received:June 13,2016 | Published: June 17, 2016

\section{Case 2}

A fifty-two-year old woman was admitted to our outpatient clinic with fatigue, headache and back pain. She has type 2 diabetes mellitus, hyperlipidemia, hashimato tiroiditis, asthma diagnosis and a history of acute pancreatittis 5years ago. She had acute pancreatitis, 3years after diagnosed with type 2 diabetes. She had no history of alcohol consumption. On physical examination she presented with blood pressure (BP) $118 / 74 \mathrm{~mm} \mathrm{Hg}$, heart rate (HR) $78 \mathrm{bpm}$, respiratory rate (RR) $19 \mathrm{rpm}$, temperature $36,8^{\circ} \mathrm{C}$, O2 Saturation 98. She had nonspesific left lower abdominal pain that intensifies with palpation and hepatomegaly of $3 \mathrm{~cm}$ below costal margin. She had no diabetic retinopathy in her eye examination. Laboratory tests showed; glucose $393 \mathrm{mg} / \mathrm{dL}$, TG $9283 \mathrm{mg} / \mathrm{dL}$, total cholesterol $1089 \mathrm{mg} / \mathrm{dL}, \mathrm{HbA} 1 \mathrm{c}$ $14 \%$, venous gas sample $\mathrm{pH} 7.38$, ketonuria and glycosuria. To exlude new pancreatitis attack; laboratory tests showed; amylase 40U/L, lipase 33U/L, abdominal ultrasound showed signs of fatty liver and abdominal MRI showed hepatomegaly $(210 \mathrm{~mm})$. Fluid therapy and continuous insulin perfusion $(0,1 \mathrm{U} / \mathrm{kg})$ iniated for hyperglicemia and HTG treatment. TG levels decreased progressively. At 5th day, TG levels dropped to $674 \mathrm{mg} / \mathrm{dL}$ and total cholesterol to $834 \mathrm{mg} / \mathrm{dL}$. At 6 th day TG was $380 \mathrm{mg} / \mathrm{dL}$. Glycemia were well controlled with subcutaneous insulin regimen (insuline glargine and insulin aspart), negative glycosuria and ketonuria. She treated with omega 3 fatty acids and fibrates on her follow-up monitoring and her TG levels were moderately high.

\section{Conclusion}

Patients with untreated diabetes mellitus and insulin deficiency commonly have HTG; this condition occurs more frequently in type 2 than in type 1 diabetes mellitus. Appropriate diabetes management reduces TG levels. ${ }^{7}$ Insulin promotes the synthesis of lipoprotein lipase, which hydrolyzes TG into fatty acids and glycerol and 
facilitates storage of the fatty acids in adipocytes. ${ }^{8}$ In a non-diabetic adolescent patient with severe HTG, a bolus dose of regular insulin $(0.1 \mathrm{U} / \mathrm{kg})$ given subcutaneously decreased serum TG from $1893 \mathrm{mg} /$ dL to $1015 \mathrm{mg} / \mathrm{dL}$ after only 4 hours. ${ }^{9}$ Treatment with insulin infusion is an effective and minimally-invasive form of rapidly treating severe HTG in addition to other pharmacological agents in both diabetes mellitus and isolated HTG patients. It is important to keep TG levels under $150 \mathrm{mg} / \mathrm{dL}$ to reduce the risk of cardiovascular morbidity, acute pancreatitis and other complications.

\section{Acknowledgements}

None.

\section{Conflict of interest}

Author declares that there is no conflict of interest.

\section{References}

1. Expert Panel on Detection, Evaluation, and Treatment of High Blood Cholesterol in Adults. Executive Summary of The Third Report of The National Cholesterol Education Program (NCEP) Expert Panel on Detection, Evaluation, And Treatment of High Blood Cholesterol In Adults (Adult Treatment Panel III). JAMA. 2001;285(19):2486-2497.

2. Sujani Poonuru, Sumedha R Pathak, Hemender S Vats, et al. Rapid Reduction of Severely Elevated Serum Triglycerides with Insulin Infusion, Gemfibrozil and Niacin. Clin Med Res. 2011;9(1):38-41.
3. Yadav D, Pitchumoni CS. Issues in hyperlipidemic pancreatitis. J Clin Gastroenterol. 2003;36(1):54-62.

4. Brunzell JD, Deeb SS. Familial lipoprotein lipase deficiency, apo CII deficiency and hepatic lipase deficiency. In: Scriver CR, editor. The Metabolic and Molecular Bases of Inherited Disease. 8th ed. NY: McGraw-Hill; 2001. p. 2789-816.

5. Brunzell JD, Schrott HG. The interaction of familial and secondary causes of hyertriglyceridemia: role in pancreatitis. Trans Assoc Am Physicians. 1973;86:245-254.

6. Jing Pang, Dick C Chan, Gerald F Watts. Origin and therapy for hypertriglyceridaemia in type 2 diabetes. World $J$ Diabetes. 2014;5(2):165-175.

7. Brunzell JD, Ayyobi AF. Dyslipidemia in themetabolicsyndromeandtype 2 diabetesmellitus. Am J Med. 2003;115(Suppl 8A):24S-28S.

8. Sadur CN, Eckel RH. Insulin stimulation of adipose tissue lipoprotein lipase. Use of the euglycemic clamp technique. J Clin Invest. 1982;69(5):1119-1125.

9. Jabbar MA, Zuhri-Yafi MI, Larrea J. Insulin therapy for a nondiabetic patient with severe hypertriglyceridemia. J Am Coll Nutr. 1998;17(5):458-461. 